\title{
Symmetrical Gas-Phase Dissociation of Non-Covalent Protein Complexes via Surface Collisions
}

Christopher M. Jones, Richard L. Beardsley, Asiri S. Galhena, Shai Dagan, Guilong Cheng, Vicki H. Wysocki*

Department of Chemistry, University of Arizona, Tucson, AZ 85721

\section{Supporting Information}




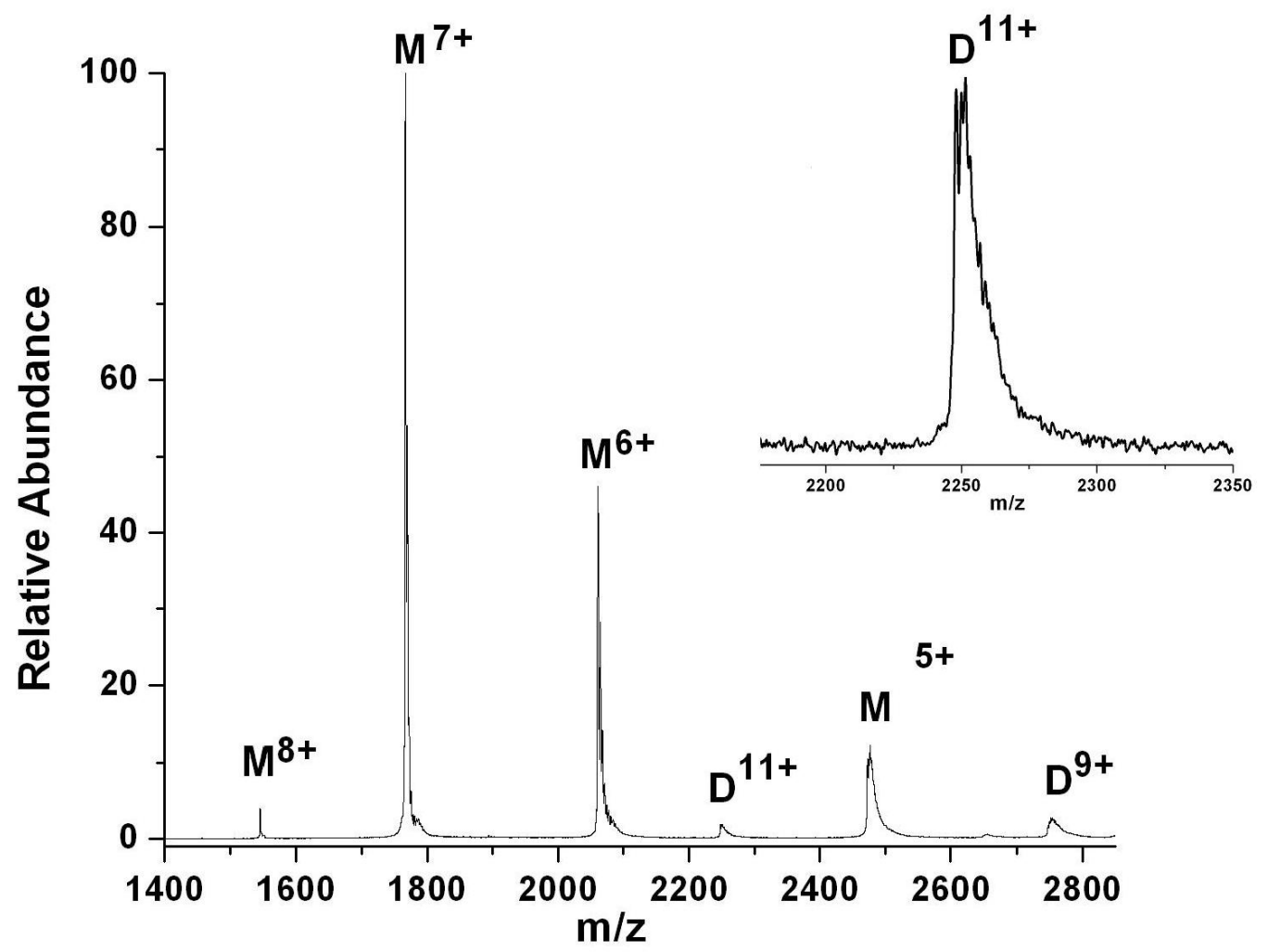

Figure S1. Nano-electrospray ionization mass spectrum of $200 \mu \mathrm{M}$ cytochrome $\mathrm{C}$ in a buffer solution of $10 \mathrm{mM}$ ammonium acetate:ammonium bicarbonate, $\mathrm{pH} 7$. Inset shows an enhancement of the $11+$ charge state of the cytochrome $\mathrm{C}$ homodimer. 
CID (a)



$\operatorname{SID}(b)$

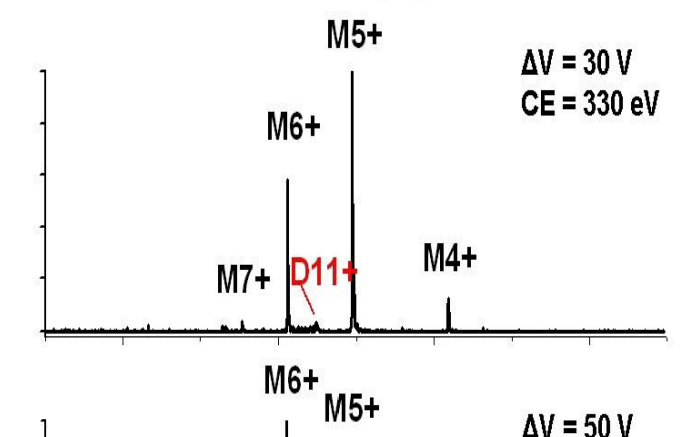

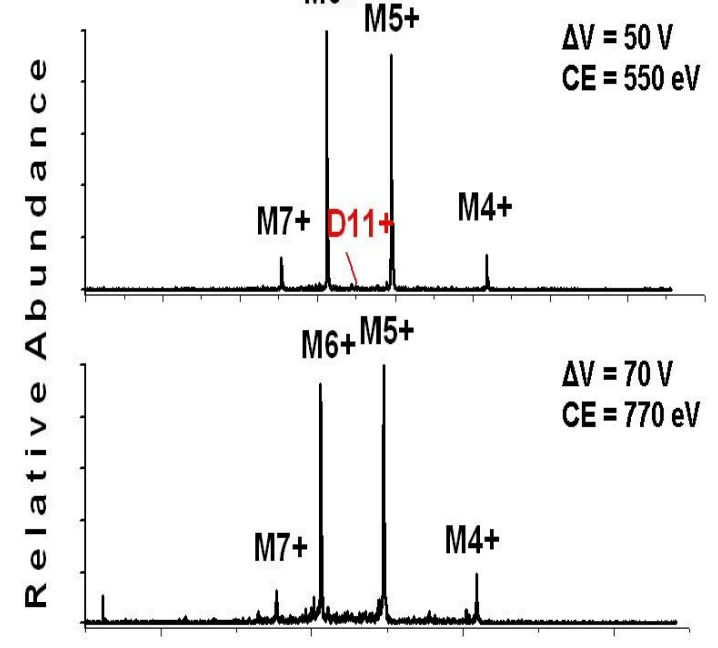

\section{Heme}

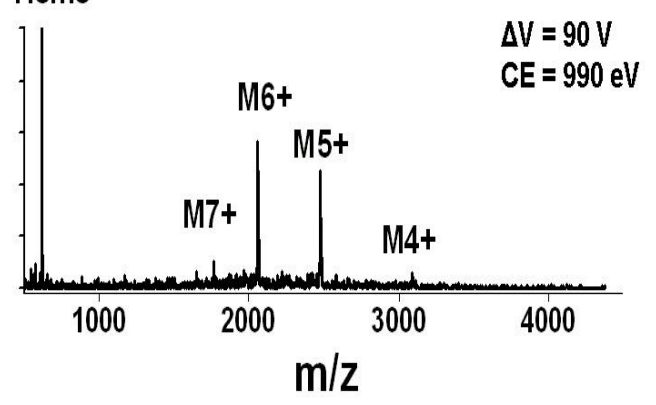

Figure S2. Energy-resolved CID (column a) and SID (column b) tandem mass spectra for the $11+$ homodimer of cytochrome $C$. The voltage difference between the source hexapole and the collision cell (CID) or the surface (SID) is listed as $\Delta \mathrm{V}$. The collision energy (CE), the product of $\Delta \mathrm{V}$ and the precursor ion charge state is also given for each spectrum. All other experimental conditions were identical for each spectrum collected. The cone voltage was set at 50 volts, in contrast to the 150 volts used for the spectra of Fig. 1 and the tube lens was maintained at 85 volts as pre-set by the manufacturer. These more conventional settings (as opposed to those used in Fig. 1) were used to show that the symmetric nature of dissociation is indeed a result of the activation method employed rather than harsh source conditions or manipulation of the kinetic energy as ions enter the TOF tube. 